in vivo $35: 363-371(2021)$

doi:10.21873/invivo.12267

\title{
Predictors for Grip Strength Loss in Patients With Chronic Liver Diseases
}

\author{
HIROKI NISHIKAWA ${ }^{1,2^{*}}$, KAZUNORI YOH ${ }^{1 *}$, HIRAYUKI ENOMOTO $^{1}$, \\ NAOTO IKEDA ${ }^{1}$, TOMOYUKI TAKASHIMA ${ }^{1}$, NOBUHIRO AIZAWA ${ }^{1}$, \\ TAKASHI NISHIMURA ${ }^{1}$, SHUHEI NISHIGUCHI $^{3}$ and HIROKO IIJIMA ${ }^{1}$ \\ ${ }^{1}$ Department of Internal Medicine, Division of Gastroenterology and Hepatology, \\ Hyogo College of Medicine, Nishinomiya, Japan; \\ ${ }^{2}$ Center for Clinical Research and Education, Hyogo College of Medicine, Nishinomiya, Japan; \\ ${ }^{3}$ Kano General Hospital, Osaka, Japan
}

\begin{abstract}
Background/Aim: To elucidate factors associated with secular changes of grip strength $(G S)$ in patients with chronic liver diseases (CLDs) $(n=241,102$ males, median age $=63$ years, 87 liver cirrhosis cases). Materials and Methods: $\triangle G S$ (kg/year) was defined as [GS value (second time) - GS value (first time)]/[time interval between the first and second time]. GS loss (GSL) was defined as $\triangle G S<0$ kg/year. Results: The median $\triangle G S$ in patients with non-LC, Child-Pugh $A(n=70)$ and Child-Pugh $B(n=17)$ were $0.3,-0.2$ and $-1.6 \mathrm{~kg} /$ year (overall $\mathrm{p}<0.0001$ ). In the multivariate analysis of factors linked to the GSL for all cases, extracellular water (ECW) to total body water (TBW) ratio was significant ( $p=0.0007)$. In the multivariate analysis in male, no significant factor was found, while in female, $E C W$ to TBW ratio was significant $(p=0.0024)$. Conclusion: Liver functional parameters can be closely linked to the GSL especially in female CLD patients.
\end{abstract}

The liver is the pivotal organ for the metabolism of the human body $(1,2)$. Advanced chronic liver diseases (CLDs) are frequently associated with disease-related sarcopenia (i.e., secondary sarcopenia) (1-6). Therefore, it is meaningful

This article is freely accessible online.

*These Authors contributed equally to this study.

Correspondence to: Hiroki Nishikawa, MD, Ph.D., Department of Internal Medicine, Division of Gastroenterology and Hepatology, Hyogo College of Medicine, 1-1, Mukogawacho, Nishinomiyashi, Hyogo 663-8501, Japan. Tel: +81 798456111, Fax: +81 798456608, e-mail: nishikawa_6392_0207@yahoo.co.jp

Key Words: Chronic liver disease, grip strength loss, secular change, liver function. to consider skeletal muscle as one organ and discuss sarcopenia in relation to organs in the medical treatment and research of liver diseases. CLD patients with sarcopenia can involve both impaired protein synthesis and accelerated muscle proteolysis in skeletal muscles $(1,2)$. A previous meta-analysis reported the close association between sarcopenia and mortality in CLD patients (4). Many highquality studies of sarcopenia led to recognition as a disease entity with the awards of an ICD 10 code in 2016 (7). In addition, the recent revisions of diagnostic criteria for sarcopenia in European or Asian guidelines have made sarcopenia research more exciting $(8,9)$.

Grip strength (GS) does not require difficult movements and can be measured easily and safely in a short time, and thus it is suitable for measuring muscle strength in daily medical care. GS, which is mainly the muscle strength of the upper body, has significant correlations with the muscle strength in the lower limbs and many other parts, and it is used as an index to assess the degree of muscle strength of the whole body (10-13). GS seems to be the main determinant of physical activity (8). Recent numerous studies have also shown that decreased GS is linked to an elevated risk of disease development, disease progression and mortality. However, the impact of skeletal muscle mass rather than GS had mainly been focused in sarcopenia researches for the past several decades (14-30). In our recent study, we emphasized the significance of GS on composite hepatic events in CLD patients (15). Hanai et al. reported that reduced GS rather than skeletal muscle mass and fat mass was significantly linked to an increased risk of mortality in cirrhotic patients (16). However, to our knowledge, data for factors related to the secular changes of GS in CLDs are scarce (31). The aim of this study was to elucidate factors associated with secular changes of GS in patients with CLDs. 


\section{Patients and Methods}

Patients. Using a retrospective computerized database, a total of 241 CLD individuals who visited our Hospital between January 2013 and April 2020 were analyzed. Diagnosis for liver cirrhosis (LC) was determined according to the current guidelines (32). All analyzed patients received GS measurement twice with an interval of at least 3 months. The most suitable intervention for each underlying liver disease was performed (32-35). The study protocol rigorously conformed to the 1975 Helsinki Declaration, and approval of ethics was obtained from the institutional review board in our hospital. An opt out method was employed.

$G S$, SMI and $\triangle G S$. A low-GS was defined as $<26 \mathrm{~kg}$ in males and $<18 \mathrm{~kg}$ in females based on the Japanese Society of Hepatology (JSH) guidelines (36). Likewise, a low-skeletal muscle index (SMI, SMI indicates appendicular muscle mass divided by height squared $\left[\mathrm{kg} / \mathrm{m}^{2}\right]$ ) was defined as $<7.0 \mathrm{~kg} / \mathrm{m}^{2}$ in males and $<5.7 \mathrm{~kg} / \mathrm{m}^{2}$ in females using bioelectrical impedance analysis (36). Sarcopenia was defined as both low-GS and low-SMI (36). $\Delta \mathrm{GS}$ (kg/year) was defined as [GS value (second time) - GS value (first time) $] \div$ [time interval between the first time and the second time (year)]. GS loss (GSL) was defined as $\Delta \mathrm{GS}<0 \mathrm{~kg} / \mathrm{year}$. We investigated factors associated with the GSL.

Statistical analyses. As for the continuous parameters, MannWhitney $U$-test, Student's t-test, analysis of variance or KruskalWallis test was employed to adequately assess differences between groups. As for the categorical parameters, Fisher's exact test or Pearson $\chi^{2}$ test was employed to assess differences between groups. Baseline significant parameters in the univariate analysis were subjected to the multivariate logistic regression analysis to choose candidate parameters. In the multivariate analyses of items associated with the GSL, the median value for each significant item in the univariate analysis was selected to classify the study cohort into the two categorical groups. In the analysis of correlation between parameters, Pearson's correlation coefficient (r) was employed. A $p<0.05$ denotes statistical significance by the statistical analysis software (JMP 14 (SAS Institute Inc., Cary, NC)).

\section{Results}

Baseline characteristics. The baseline characteristics of the analyzed subjects $(n=241,102$ males, median age $=63$ years $)$ are presented in Table I. There were 178 patients (73.9\%) with albumin-bilirubin (ALBI) grade 1, 60 (24.9\%) with ALBI grade 2 and 3 (1.2\%) with ALBI grade 3. LC was seen in 87 patients (36.1\%: Child-Pugh $\mathrm{A} / \mathrm{B} / \mathrm{C}$ in $70 / 17 / 0$ patients, respectively). Eight male patients (7.8\%) had a GS decrease, while 28 female patients $(20.1 \%)$ had a GS decrease (36). Twenty-seven male patients $(26.5 \%)$ had an SMI decrease, while 47 female patients (33.8\%) had an SMI decrease (36). Collectively, sarcopenia was found in 17 patients $(7.1 \%)$ [4 male patients $(3.9 \%)$ and 13 female patients $(9.4 \%)]$. The median time interval between the first time GS measurement and the second time GS measurement was 1.41 years. The median [interquartile range (IQR)] $\Delta \mathrm{GS}(\mathrm{kg} / \mathrm{year})$ for all cases was $0(-1.0,0.9) \mathrm{kg} /$ year (Figure $1 \mathrm{~A})$.
Table I. Baseline characteristics $(n=241)$.

\begin{tabular}{lc}
\hline Variables & All cases $(\mathrm{n}=241)$ \\
\hline Age (years) & $63(52,70)$ \\
Gender, male/female & $102 / 139$ \\
Liver disease etiology HCV/HBV/others & $154 / 21 / 66$ \\
Presence of sarcopenia, yes/no & $17 / 224$ \\
Presence of LC, yes/no & $87 / 154$ \\
Body mass index $\left(\mathrm{kg} / \mathrm{m}^{2}\right)$ & $22.8(20.5,25.7)$ \\
SMI $\left(\mathrm{kg} / \mathrm{m}^{2}\right), \mathrm{male}$ & $7.635(6.9375,8.1225)$ \\
SMI $\left(\mathrm{kg} / \mathrm{m}^{2}\right)$, female & $5.965(5.52,6.49)$ \\
Grip strength $(\mathrm{kg}), \mathrm{male}$ & $34.375(29.675,40.3375)$ \\
Grip strength $(\mathrm{kg}), \mathrm{female}$ & $20.95(18.75,23.35)$ \\
ECW to TBW $\mathrm{ratio}$ & $0.388(0.384,0.390)$ \\
Total bilirubin $(\mathrm{mg} / \mathrm{dl})$ & $0.8(0.6,1.0)$ \\
Serum albumin $(\mathrm{g} / \mathrm{dl})$ & $4.2(3.9,4.4)$ \\
ALBI score & $-2.82(-3.035,-2.565)$ \\
ALBI grade, $1 / 2 / 3$ & $178 / 60 / 3$ \\
Prothrombin time $(\mathrm{INR})$ & $1.06(1.01,1.12)$ \\
Platelet count $\left(\times 10^{4} / \mathrm{mm}^{3}\right)$ & $17.3(11.9,22.55)$ \\
AST $(\mathrm{IU} / \mathrm{l})$ & $27(21,37)$ \\
ALT $(\mathrm{IU} / \mathrm{l})$ & $23(15,40)$ \\
eGFR $\left(\mathrm{ml} / \mathrm{min} / 1.73 \mathrm{~m}^{2}\right)$ & $82(71,96.5)$ \\
\hline
\end{tabular}

Data are expressed as number or median value (interquartile range). HCV: Hepatitis C virus; HBV: hepatitis B virus; LC: liver cirrhosis; SMI: skeletal muscle index; ECW: extracellular water; TBW: total body water; ALBI: albumin-bilirubin; INR: international normalized ratio; AST: aspartate aminotransferase; ALT: alanine aminotransferase; eGFR: estimated glomerular filtration rate.

$\triangle G S$ (kg/year) according to gender, age, sarcopenia, body mass index (BMI), ALBI grade, Child-Pugh classification and liver disease etiology. The median (IQR) $\Delta \mathrm{GS}$ ( $\mathrm{kg} /$ year) in males $(\mathrm{n}=102)$ and females $(\mathrm{n}=139)$ were $0.3(-1.05,1.1)$ $\mathrm{kg} /$ year and $-0.2(-1.0,0.7) \mathrm{kg} /$ year, respectively, $(p=0.5429)$ (Figure $1 \mathrm{~B}, \mathrm{C}$ and $2 \mathrm{~A})$. The median (IQR) $\Delta \mathrm{GS}(\mathrm{kg} / \mathrm{year})$ in patients aged 65 years or more $(n=109)$ and less than 65 years $(\mathrm{n}=132)$ were $-0.2(-1.4,0.65) \mathrm{kg} /$ year and $0.3(-0.6,1.175)$ $\mathrm{kg} /$ year, respectively, $(p=0.0672)$ (Figure 2B). The median (IQR) $\Delta \mathrm{GS}(\mathrm{kg} /$ year) in patients with sarcopenia $(\mathrm{n}=17)$ and without sarcopenia $(\mathrm{n}=224)$ were $0.1(-0.35,1.1) \mathrm{kg} /$ year and $0(-1.0,0.9) \mathrm{kg} /$ year, respectively, $(p=0.5950)$ (Figure 2C). The median (IQR) $\Delta \mathrm{GS}(\mathrm{kg} /$ year) in patients with $\mathrm{BMI} \geq 25$ $\mathrm{kg} / \mathrm{m}^{2}(\mathrm{n}=72)$ and $<25 \mathrm{~kg} / \mathrm{m}^{2}(\mathrm{n}=169)$ were $-0.1(-1.3,0.7)$ $\mathrm{kg} /$ year and $0.1(-0.7,0.975) \mathrm{kg} /$ year, respectively, $(p=0.4789)$ (Figure 2D). The median (IQR) $\Delta \mathrm{GS}$ (kg/year) in patients with ALBI grade $1(n=178)$ and ALBI grade 2 or $3(n=63)$ were $0.2(-0.6,1.0) \mathrm{kg} /$ year and $-0.5(-1.9,0.5) \mathrm{kg} /$ year, respectively, $(p=0.0064)$ (Figure $2 \mathrm{E}$ ). The median (IQR) $\Delta \mathrm{GS}$ $(\mathrm{kg} /$ year $)$ in patients with non-LC $(\mathrm{n}=154)$, Child-Pugh A $(\mathrm{n}=70)$ and Child-Pugh $\mathrm{B}(\mathrm{n}=17)$ were $0.3(-0.6,1.2)$ $\mathrm{kg} /$ year, $-0.2(-1.425,0.325) \mathrm{kg} /$ year and $-1.6(-4.5,-0.1)$ $\mathrm{kg} /$ year, respectively [ $p=0.0002$ (non-LC vs. Child-Pugh A), $p=0.0255$ (Child-Pugh A vs. B), $p<0.0001$ (non-LC vs. Child- 

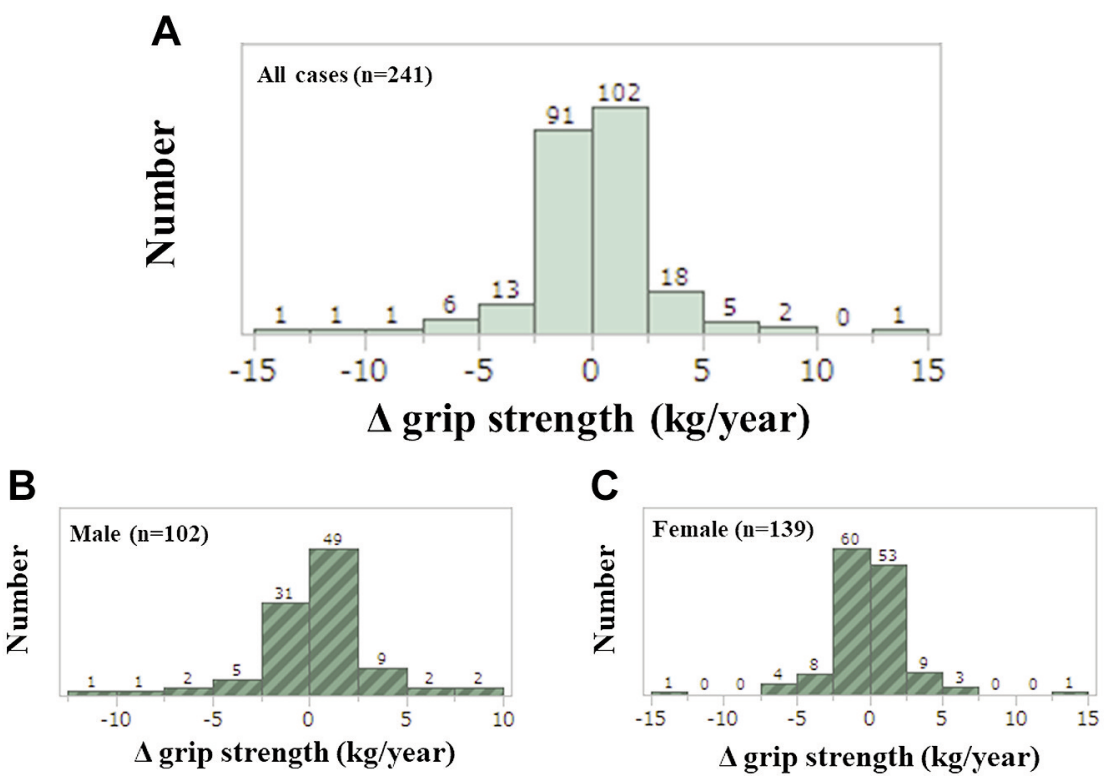

Figure 1. The distribution of $\Delta G S$ (kg/year) [GS value (second time) - GS value (first time)] $\div$ [time interval between the first time and the second time (year)] for all cases $(n=241)(A)$, male cases $(n=102))(B)$ and female cases $(n=139)(C)$.
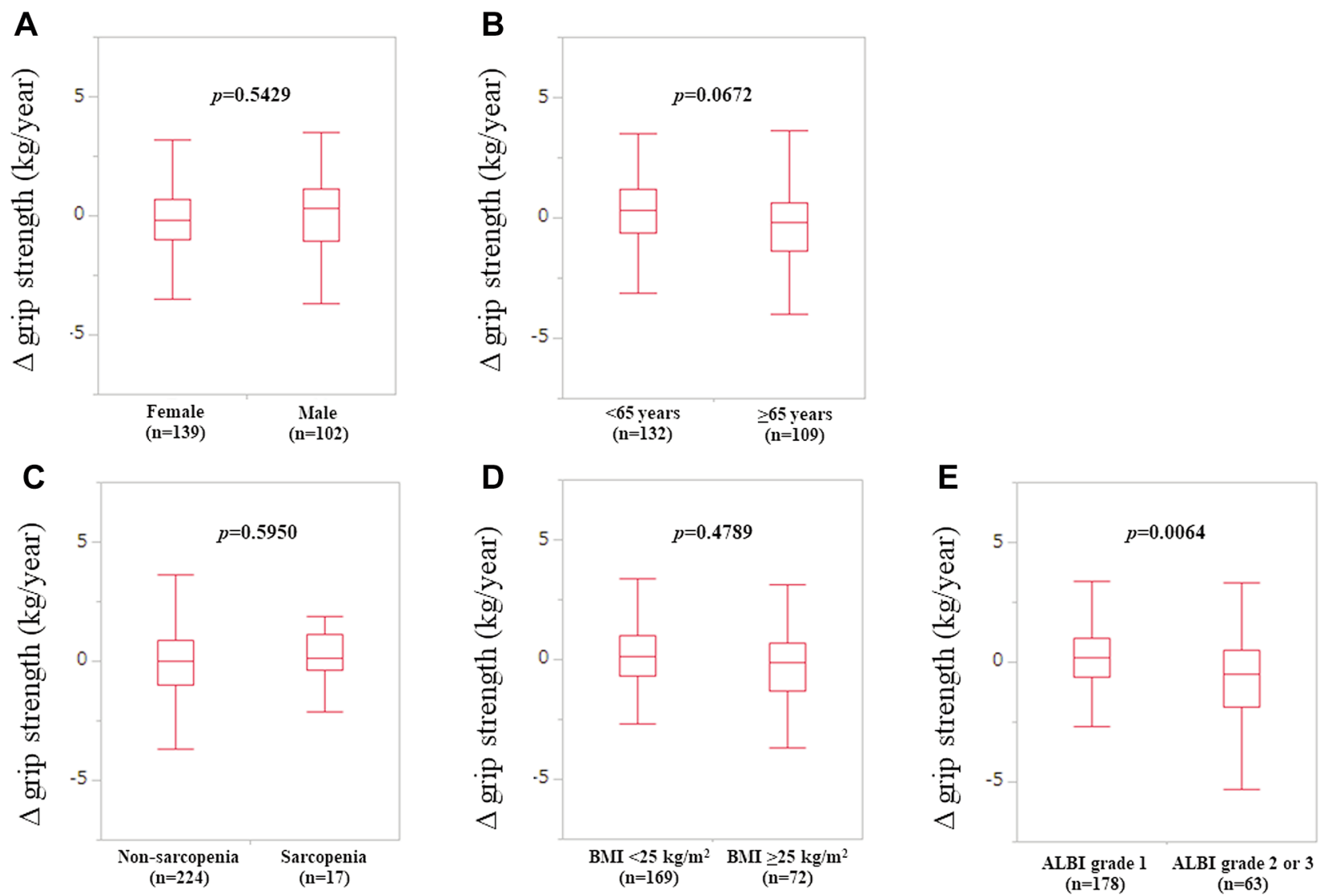

Figure 2. $\Delta G S$ (kg/year) according to gender $(A)$, age (B), sarcopenia $(C)$, body mass index (Figure $2 D)$, albumin-bilirubin grade (E). 
A

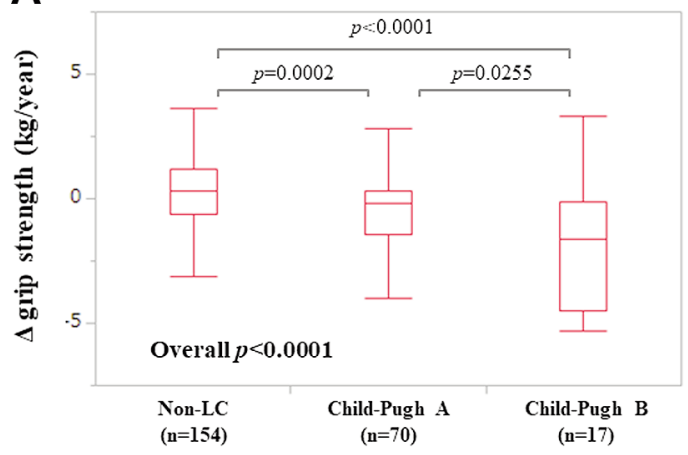

B

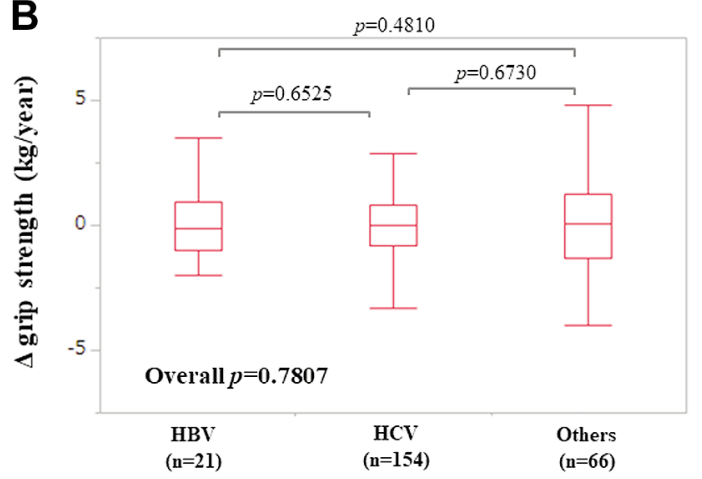

Figure 3. $\Delta G S$ (kg/year) according to Child-Pugh classification (A) and liver disease etiology (B).

Pugh B) and overall $p<0.0001$ ] (Figure 3A). The median (IQR) $\Delta \mathrm{GS}(\mathrm{kg} / \mathrm{year})$ in patients with hepatitis B virus (HBV, $\mathrm{n}=21)$, hepatitis $\mathrm{C}$ virus $(\mathrm{HCV}, \mathrm{n}=154)$ and others $(\mathrm{n}=66)$ were $-0.1(-1.0,0.95) \mathrm{kg} /$ year, $0(-0.775,0.8) \mathrm{kg} /$ year and $0.05(-1.325,1.225) \mathrm{kg} /$ year, respectively $[p=0.6525(\mathrm{HBV}$ $v s . \mathrm{HCV}$ ), $p=0.6730$ (HCV vs. others), $p=0.4810$ (HBV vs. others) and overall $p=0.7807$ ] (Figure 3B).

Correlation between $\triangle G S$ and baseline continuous parameters according to gender. Regarding correlations between $\Delta \mathrm{GS}$ and baseline continuous parameters, significant associations were found in age ( $\mathrm{r}=-0.24$ and $p=0.0171)$ as for male gender, and total bilirubin ( $\mathrm{r}=-0.26$ and $p=0.0023)$, serum albumin $(\mathrm{r}=0.21$ and $p=0.0148)$, ALBI score $(\mathrm{r}=-0.25$ and $p=0.0027)$, prothrombin time-INR (PT-INR) $(\mathrm{r}=0.30$ and $p=0.0003)$, platelet count $(\mathrm{r}=0.31$ and $p=0.0002)$ and extracellular water (ECW) to total body water (TBW) ratio ( $\mathrm{r}=-0.42$ and $p<0.0001)$ as for female (Table II).

Uni- and multivariate analyses of factors linked to the GSL for all cases. For all cases, GSL was found in 113 patients $(46.9 \%)$. The univariate analysis of factors associated with the GSL identified that 6 had values of $p<0.05$ : age $(p=0.0006)$, presence of LC $(p<0.0001)$, serum albumin $(p=0.0015)$, ALBI score $(p=0.0009)$, PT-INR $(p=0.0040)$ and ECW to TBW ratio $(p<0.0001)$ (Table III). Serum albumin was excluded from the multivariate analysis as ALBI includes serum albumin. In the multivariate analysis of the remaining 5 factors, ECW to TBW ratio was found to be significant $(p=0.0007)$, while presence of LC tended to be significant $(p=0.0706)$. Corresponding odds ratio (OR) and $95 \%$ confidence interval (CI) for each variable were demonstrated in Table IV.

Uni- and multivariate analyses of factors linked to the GSL for male cases. For male cases, GSL was found in 40 patients $(39.2 \%)$. The univariate analysis of factors
Table II. Correlation between $\Delta G S$ ( $k g /$ year) and baseline continuous parameters according to gender.

\begin{tabular}{lccrrr}
\hline & \multicolumn{2}{c}{ Male } & & \multicolumn{2}{c}{ Female } \\
\cline { 2 - 3 } \cline { 5 - 6 } & $\mathrm{r}$ & $p$-Value & & $\mathrm{r}$ & $p$-Value \\
\hline Age & -0.24 & 0.0171 & & -0.09 & 0.2810 \\
BMI & -0.04 & 0.7115 & & -0.02 & 0.8590 \\
Baseline GS & -0.02 & 0.8756 & & 0.07 & 0.3913 \\
Baseline SMI & -0.02 & 0.8755 & & 0.03 & 0.7660 \\
Total bilirubin & -0.006 & 0.9538 & & -0.26 & 0.0023 \\
Serum albumin & 0.17 & 0.0850 & & 0.21 & 0.0148 \\
ALBI score & -0.15 & 0.1238 & & -0.25 & 0.0027 \\
Prothrombin time (INR) & 0.12 & 0.2197 & & 0.30 & 0.0003 \\
Platelet count & -0.11 & 0.2787 & & 0.31 & 0.0002 \\
AST & 0.09 & 0.3859 & & -0.09 & 0.2874 \\
ALT & 0.18 & 0.0724 & & 0.02 & 0.7740 \\
eGFR & 0.09 & 0.3841 & & -0.08 & 0.3312 \\
ECW to TBW ratio & -0.14 & 0.1552 & & -0.42 & $<0.0001$ \\
\hline
\end{tabular}

BMI: Body mass index; GS: grip strength; SMI: skeletal muscle index; ALBI: albumin-bilirubin; INR: international normalized ratio; AST: aspartate aminotransferase; ALT: alanine aminotransferase; eGFR: estimated glomerular filtration rate; ECW: extracellular water; TBW: total body water.

associated with the GSL identified that 4 had values of $p<0.05$ : age $(p=0.0044)$, presence of LC $(p=0.0380)$, estimated glomerular filtration rate (eGFR) $(p=0.0273)$ and ECW to TBW ratio ( $p=0.0217$ ) (Table V). In the multivariate analysis of the 4 factors, no significant factor was found, while eGFR tended to be significant $(p=0.0826)$. Corresponding OR and 95\% CI for each variable were demonstrated in Table VI.

Uni- and multivariate analyses of factors linked to the GSL for female cases. For female cases, GSL was found in 73 
Table III. Univariate analysis of factors linked to GSL for all cases $(n=241)$.

\begin{tabular}{lccc}
\hline & GSL, yes $(\mathrm{n}=113)$ & GSL, no (n=128) & $p$-Value \\
\hline Age (years) & $66(57,71.5)$ & $60(47,67)$ & 0.0006 \\
Etiology, HCV/HBV/others & $70 / 11 / 32$ & $84 / 10 / 34$ & 0.7989 \\
Gender (male/female) & $40 / 73$ & $62 / 66$ & 0.0500 \\
Presence of LC, yes/no & $56 / 57$ & $31 / 97$ & 0.0001 \\
Presence of sarcopenia, yes/no & $6 / 107$ & $11 / 117$ & 0.4507 \\
BMI $\left(\mathrm{kg} / \mathrm{m}^{2}\right.$ ) & $23.1(20.3,26.1)$ & $22.65(20.525,25)$ & 0.7322 \\
Total bilirubin (mg/dl) & $0.8(0.7,1.15)$ & $0.8(0.6,1.0)$ & 0.1903 \\
Serum albumin $(\mathrm{g} / \mathrm{dl})$ & $4.1(3.8,4.3)$ & $4.25(4.0,4.5)$ & 0.0015 \\
ALBI score & $-2.74(-2.935,-2.375)$ & $-2.885(-3.11,-2.6525)$ & 0.0009 \\
Prothrombin time $(\mathrm{INR})$ & $1.08(1.03,1.14)$ & $1.045(1.0,1.1)$ & 0.0040 \\
Platelet count $\left(\times 10^{4} / \mathrm{mm}^{3}\right)$ & $16(11.1,20.65)$ & $18(12.825,23.1)$ & 0.0501 \\
AST (IU/l) & $28(22,39)$ & $25.5(19,35)$ & 0.9843 \\
ALT (IU/l) & $21(14.5,35)$ & $24(16,42)$ & 0.2369 \\
eGFR (ml/min/1.73m $\left.\mathrm{m}^{2}\right)$ & $79(67,91.5)$ & $84.5(73.25,99)$ & 0.0770 \\
ECW to TBW ratio & $0.392(0.396,0.397)$ & $0.386(0.382,0.390)$ & $<0.0001$ \\
\hline
\end{tabular}

Data are shown as median (interquartile range). GSL: Grip strength loss; HCV: hepatitis C virus; HBV: hepatitis B virus; LC: liver cirrhosis; BMI: body mass index; ALBI: albumin-bilirubin; INR: international normalized ratio; AST: aspartate aminotransferase; ALT: alanine aminotransferase; eGFR: estimated glomerular filtration rate; ECW: extracellular water; TBW: total body water.

patients $(53.3 \%)$. The univariate analysis of factors associated with the GSL identified that 6 had values of $p<0.05$ : presence of LC ( $p=0.0003)$, serum albumin $(p=0.0239)$, ALBI score $(p=0.0111)$, PT-INR $(p=0.0034)$, platelet count $(p=0.0008)$ and ECW to TBW ratio $(p<0.0001)$ (Table VII). Serum albumin was excluded for the multivariate analysis as ALBI includes serum albumin. In the multivariate analysis of the remaining 5 factors, ECW to TBW ratio was found to be significant $(p=0.0024)$, while ALBI score tended to be significant $(p=0.0895)$. Corresponding OR and 95\% CI for each variable were demonstrated in Table VIII.

\section{Discussion}

GS is the main determinant of physical activity (8). GS well reflects the degree of muscle strength of the whole body (1013). GS can be a marker of nutritional status because muscle function responds early to nutritional deficiencies (10). GS measurement is a key part of the JSH assessment criteria for sarcopenia in liver disease (36). However, in the current European guidelines, Asian guidelines or JSH guidelines, description of secular changes in GS is not found anywhere $(8,9,36)$. Few data with regard to GSL in CLD patients are currently available (31). Thus, elucidating risk factors for the GSL in patients with CLDs seems to be clinically meaningful.

In our multivariate analysis for all cases, ECW to TBW ratio was found to be an independent factor and presence of LC tended to be a significant factor linked to the GSL. ECW to TBW ratio in CLDs represents edematous status and liver function (37). Management of edematous status in CLDs should be pivotal for avoiding GSL. In our previous
Table IV. Multivariate analysis of factors linked to GSL for all cases.

\begin{tabular}{lccc}
\hline & $\begin{array}{c}\text { Odds } \\
\text { ratio }\end{array}$ & $\begin{array}{c}95 \% \text { confidence } \\
\text { interval }\end{array}$ & $p$-Value \\
\hline Age $\geq 63$ years & 1.101 & $0.589-2.059$ & 0.7624 \\
Presence of LC & 1.877 & $0.949-3.714$ & 0.0706 \\
ALBI score $\geq-2.82$ & 1.526 & $0.854-2.725$ & 0.1546 \\
Prothrombin time $($ INR $) \geq 1.06$ & 1.113 & $0.580-2.101$ & 0.7416 \\
ECW to TBW ratio $\geq 0.388$ & 3.069 & $1.590-5.921$ & 0.0007 \\
\hline
\end{tabular}

LC: Liver cirrhosis; ALBI: albumin-bilirubin; INR: international normalized ratio; ECW: extracellular water; TBW: total body water.

investigation, we reported the significant negative correlation between ECW to TBW ratio and walking speed in patients with CLDs, which are similar to the current data (38). As shown in Figure 3, the stepwise decrease of $\Delta \mathrm{GS}$ was found according to the liver disease severity. While Hiraoka et al. reported the significant correlation between serum albumin level and the GSL, which are in line with our data (31).

In the correlation between $\Delta \mathrm{GS}$ and baseline continuous parameters according to gender, and in the multivariate analyses of factors linked to the GSL according to gender, large differences between male and female were found. Age significantly correlated with $\Delta \mathrm{GS}$ in male, while not in female. Total bilirubin, serum albumin, ALBI score, PT-INR, platelet count and ECW to TBW ratio significantly correlated with $\triangle \mathrm{GS}$ in females, while not in males. ECW to TBW ratio was an independent predictor linked to the GSL in females, while not in males. Hanai et al. reported that GS was 
in vivo 35 : $363-371(2021)$

Table V. Univariate analysis of factors linked to GSL for male cases $(n=102)$.

\begin{tabular}{lccc}
\hline & GSL, yes $(\mathrm{n}=40)$ & GSL, no $(\mathrm{n}=62)$ & $p$-Value \\
\hline Age (years) & $65.5(54.25,71.75)$ & $55.5(45.75,65)$ & 0.0044 \\
Etiology, HCV/HBV/others & $22 / 6 / 12$ & $40 / 7 / 15$ & $18 / 44$ \\
Presence of LC, yes/no & $20 / 20$ & $3 / 59$ & 0.6267 \\
Presence of sarcopenia, yes/no & $1 / 39$ & $23.05(21.4,25.55)$ & 0.0380 \\
BMI $\left(\mathrm{kg} / \mathrm{m}^{2}\right)$ & $23.5(21.8,25.8)$ & $0.8(0.6,1.1)$ & 0.9999 \\
Total bilirubin (mg/dl) & $0.9(0.7,1.2)$ & $4.25(4.0,4.5)$ & 0.9119 \\
Serum albumin $(\mathrm{g} / \mathrm{dl})$ & $4.1(3.7,4.4)$ & $-2.87(-3.13,-2.65)$ & 0.3041 \\
ALBI score & $2.755(-2.9375,-2.2475)$ & $1.05(1.0,1.13)$ & 0.0896 \\
Prothrombin time $(\mathrm{INR})$ & $1.08(1.03,1.155)$ & $16.45(11.7,22.15)$ & 0.0697 \\
Platelet count $\left(\times 10^{4} / \mathrm{mm}^{3}\right)$ & $17.4(11.8,22.5)$ & $27.5(20.5,38.25)$ & 0.2339 \\
AST (IU/l) & $26(23.25,38.75)$ & $30(16.75,48.5)$ & 0.6005 \\
ALT (IU/l) & $24.5(18.25,43)$ & $87(78.75,107.25)$ & 0.5790 \\
eGFR (ml/min/ $\left.1.73 \mathrm{~m}^{2}\right)$ & $78.5(67,97.75)$ & $0.384(0.380,0.388)$ & 0.1954 \\
ECW to TBW ratio & $0.3875(0.381,0.394)$ & 0.0273 \\
\hline
\end{tabular}

Data are shown as median (interquartile range). GSL: Grip strength loss; HCV: hepatitis C virus; HBV: hepatitis B virus; LC: liver cirrhosis; BMI: body mass index; ALBI: albumin-bilirubin; INR: international normalized ratio; AST: aspartate aminotransferase; ALT: alanine aminotransferase; eGFR: estimated glomerular filtration rate; ECW: extracellular water; TBW: total body water.

independently associated with mortality regardless of gender in LC patients, however, as for secular changes in GS in patients with CLDs, clinicians should be fully aware of gender differences (16). On the other hand, in the multivariate analysis for the GSL in male, eGFR tended to be significant. A previous study reported that in communitydwelling older males $(n=789)$, mild-to-moderate renal impairment at baseline was associated with GS decline, which is in agreement of our results (39).

Sung et al. reported that encephalopathy, higher level of Wisteria floribunda agglutinin-positive Mac-2 binding protein (liver fibrosis marker), advanced age, and sarcopenia were independent adverse predictors for skeletal muscle mass loss in 166 LC patients (40). While contrary to our expectations, sarcopenia and advanced age were not independent factors linked to the GSL in our results. In this study, sarcopenia was found in only 17 patients $(7.1 \%)$ (4 male patients and 13 female patients), and the small number of sarcopenic patients may be one of possible causes of our results. In addition, the severity of underlying liver disease rather than advanced age may be associated with the GSL.

According to the report of Japan sports agency (JSA), the median values of GS in patients aged 60-64 years were 42.85 $\mathrm{kg}$ in male and $26.3 \mathrm{~kg}$ in female, while in our data (median age $=63$ years), the median values of GS were $34.375 \mathrm{~kg}$ in males and $20.95 \mathrm{~kg}$ in females, which were lower than the JSA data. These may be attributed to the disease-related muscle functional decline. JSA also reported that GS peaks at 35 to 39 years for male and 40 to 44 years for female, and then decreases with aging. In our data, there were 128 patients $(53.1 \%)$ without GSL. In the analyzed subjects, the most suitable intervention for each underlying liver disease was
Table VI. Multivariate analysis of factors linked to GSL for male cases.

\begin{tabular}{lccc}
\hline & $\begin{array}{c}\text { Odds } \\
\text { ratio }\end{array}$ & $\begin{array}{c}95 \% \text { confidence } \\
\text { interval }\end{array}$ & $p$-Value \\
\hline Age $\geq 63$ years & 1.438 & $0.512-4.039$ & 0.4923 \\
Presence of LC & 1.799 & $0.693-4.671$ & 0.2290 \\
eGFR $<82 \mathrm{ml} / \mathrm{min} / 1.73 \mathrm{~m}^{2}$ & 2.144 & $0.901-5.901$ & 0.0826 \\
ECW to TBW ratio $\geq 0.388$ & 1.555 & $0.526-4.602$ & 0.4271 \\
\hline
\end{tabular}

LC: Liver cirrhosis; eGFR: estimated glomerular filtration rate; ECW: extracellular water; TBW: total body water.

performed during the follow-up period. These interventions may lead to the maintenance of GS value. However, further examinations are required to confirm whether medical interventions ameliorate GS value in CLD patients.

Several limitations to our study must be acknowledged. First, this single-center study had a retrospective nature. Second, our cohort was heterogeneous including various etiologies for underlying liver diseases and various degrees of liver functional reserve. Third, various interventions for each subject have been done during the follow-up period, making bias for the interpretation of changes of GS values. Fourth, our results were derived from data of only Japanese CLD patients and our study cohort did not include ChildPugh C patients. Finally, GS value can vary depending on patient conditions. Caution must be, therefore, taken in interpreting the results. Despite the limitations, our study results denote that baseline liver functional parameters are closely linked to the GSL especially in female CLD patients. In conclusion, we would like to emphasize the importance 
Table VII. Univariate analysis of factors linked to GSL for female cases $(n=139)$.

\begin{tabular}{lccc}
\hline & GSL, yes $(\mathrm{n}=73)$ & GSL, no $(\mathrm{n}=66)$ & $p$-Value \\
\hline Age (years) & $66(58,71.5)$ & $63.5(53,69.25)$ & 0.1296 \\
Etiology, HCV/HBV/others & $48 / 5 / 20$ & $44 / 3 / 19$ & 0.8403 \\
Presence of LC, yes/no & $36 / 37$ & $13 / 52$ & 0.0003 \\
Presence of sarcopenia, yes/no & $5 / 68$ & $8 / 58$ & 0.3844 \\
BMI $\left(\mathrm{kg} / \mathrm{m}^{2}\right)$ & $22.4(19.575,26.475)$ & $22.1(20.075,24.25)$ & 0.5306 \\
Total bilirubin (mg/dl) & $0.8(0.7,1.05)$ & $0.7(0.575,0.9)$ & 0.3002 \\
Serum albumin $(\mathrm{g} / \mathrm{dl})$ & $4.1(3.9,4.3)$ & $4.25(4.0,4.5)$ & 0.0239 \\
ALBI score & $-2.74(-2.935,-2.51)$ & $-2.935(-3.08,-2.67)$ & 0.0111 \\
Prothrombin time $(\mathrm{INR})$ & $1.08(1.025,1.135)$ & $1.035(0.99,1.0925)$ & 0.0034 \\
Platelet count $\left(\times 10^{4} / \mathrm{mm}^{3}\right)$ & $15.3(10.65,20.5)$ & $19.15(13.7,24.675)$ & 0.0008 \\
AST (IU/l) & $28(22,39)$ & $24(18.75,33)$ & 0.4537 \\
ALT (IU/l) & $19(13,31.5)$ & $20.5(13,32.75)$ & 0.8467 \\
eGFR (ml/min/1.73m $\left.\mathrm{m}^{2}\right)$ & $80(70,90.5)$ & $82(65.75,91)$ & 0.9114 \\
ECW to TBW ratio & $0.393(0.390,0.399)$ & $0.387(0.385,0.39425)$ & 0.0011 \\
\hline
\end{tabular}

Data are shown as median (interquartile range). GSL: Grip strength loss; HCV: hepatitis C virus; HBV: hepatitis B virus; LC: liver cirrhosis; BMI: body mass index; ALBI: albumin-bilirubin; INR: international normalized ratio; AST: aspartate aminotransferase; ALT: alanine aminotransferase; eGFR: estimated glomerular filtration rate; ECW: extracellular water; TBW: total body water.

of baseline liver function as a useful predictor for the GSL in patients with CLDs.

\section{Conflicts of Interest}

The Authors declare no conflicts of interest.

\section{Authors' Contributions}

Data curation, Hiroki Nishikawa, Kazunori Yoh, Hirayuki Enomoto, Naoto Ikeda, Tomoyuki Takashima, Nobuhiro Aizawa and Takashi Nishimura; Formal analysis, Hiroki Nishikawa; Supervision, Shuhei Nishiguchi and Hiroko Iijima; Writing - original draft, Hiroki Nishikawa and Kazunori Yoh; Writing - review \& editing, Hirayuki Enomoto.

\section{Acknowledgements}

The Authors would like to thank Yasuko Higuchi in our hospital for the anthropometry measurement. This work was partly supported by Hyogo Innovative Challenge, Hyogo College of Medicine, Japan.

\section{References}

1 Bunchorntavakul C and Reddy KR: Review article: malnutrition/sarcopenia and frailty in patients with cirrhosis. Aliment Pharmacol Ther 51: 64-77, 2020. PMID: 31701570. DOI: 10.1111/apt.15571

2 Aby ES and Saab S: Frailty, sarcopenia, and malnutrition in cirrhotic patients. Clin Liver Dis 23: 589-605, 2019. PMID: 31563213. DOI: $10.1016 /$ j.cld 2019.06 .001

3 Nishikawa H, Enomoto H, Ishii A, Iwata Y, Miyamoto Y, Ishii N, Yuri Y, Hasegawa K, Nakano C, Nishimura T, Yoh K, Aizawa N, Sakai Y, Ikeda N, Takashima T, Takata R, Iijima H and
Table VIII. Multivariate analysis of factors linked to GSL for female cases.

\begin{tabular}{lccc}
\hline & $\begin{array}{c}\text { Odds } \\
\text { ratio }\end{array}$ & $\begin{array}{c}95 \% \text { confidence } \\
\text { interval }\end{array}$ & $p$-Value \\
\hline Presence of $\mathrm{LC}$ & 1.541 & $0.559-4.250$ & 0.4045 \\
ALBI score $\geq-2.82$ & 1.943 & $0.903-4.181$ & 0.0895 \\
Prothrombin time $(\mathrm{INR}) \geq 1.06$ & 1.088 & $0.468-2.530$ & 0.8439 \\
Platelet count $<17.3 \times 104 / \mathrm{mm}^{3}$ & 1.813 & $0.769-4.272$ & 0.1752 \\
ECW to TBW ratio $\geq 0.388$ & 3.569 & $1.544-8.246$ & 0.0024 \\
\hline
\end{tabular}

LC: Liver cirrhosis; ALBI: albumin-bilirubin; INR: international normalized ratio; ECW: extracellular water; TBW: total body water.

Nishiguchi S: Elevated serum myostatin level is associated with worse survival in patients with liver cirrhosis. J Cachexia Sarcopenia Muscle 8: 915-925, 2017. PMID: 28627027. DOI: $10.1002 /$ jcsm. 12212

4 Kim G, Kang SH, Kim MY and Baik SK: Prognostic value of sarcopenia in patients with liver cirrhosis: A systematic review and meta-analysis. PLoS One 12: e0186990, 2017. PMID: 29065187. DOI: 10.1371/journal.pone.0186990

5 Meyer F and Valentini L: Disease-related malnutrition and sarcopenia as determinants of clinical outcome. Visc Med 35: 282-291, 2019. PMID: 31768391. DOI: 10.1159/000502867

6 Chang KV, Chen JD, Wu WT, Huang KC, Lin HY and Han DS: Is sarcopenia associated with hepatic encephalopathy in liver cirrhosis? A systematic review and meta-analysis. J Formos Med Assoc 118: 833-842, 2019. PMID: 30279030. DOI: 10.1016/j.jfma.2018.09.011

7 Anker SD, Morley JE and von HS: Welcome to the ICD-10 code for sarcopenia. J Cachexia Sarcopenia Muscle 7: 512-514, 2016. PMID: 27891296. DOI: 10.1002/jcsm.12147 
8 Chen LK, Woo J, Assantachai P, Auyeung TW, Chou MY, Iijima K, Jang HC, Kang L, Kim M, Kim S, Kojima T, Kuzuya M, Lee JSW, Lee SY, Lee WJ, Lee Y, Liang CK, Lim JY, Lim WS, Peng LN, Sugimoto K, Tanaka T, Won CW, Yamada M, Zhang T, Akishita M, and Arai H: Asian Working Group for Sarcopenia: 2019 Consensus Update on Sarcopenia Diagnosis and Treatment. J Am Med Dir Assoc 21: 300-307.e2, 2020. PMID: 32033882. DOI: $10.1016 /$ j.jamda.2019.12.012

9 Cruz-Jentoft AJ, Bahat G, Bauer J, Boirie Y, Bruyère O, Cederholm T, Cooper C, Landi F, Rolland Y, Sayer AA, Schneider SM, Sieber CC, Topinkova E, Vandewoude M, Visser $\mathrm{M}$ and Zamboni M; Writing Group for the European Working Group on Sarcopenia in Older People 2 (EWGSOP2), and the Extended Group for EWGSOP2: Sarcopenia: revised European consensus on definition and diagnosis. Age Ageing 48: 16-31, 2019. PMID: 30312372. DOI: 10.1093/ageing/afy169

10 Norman K, Stobäus N, Gonzalez MC, Schulzke JD amd Pirlich $\mathrm{M}$ : Hand grip strength: outcome predictor and marker of nutritional status. Clin Nutr. 30: 135-142, 2011. PMID: 21035927. DOI: $10.1016 /$ j.clnu.2010.09.010

11 Bohannon RW: Hand-grip dynamometry predicts future outcomes in aging adults. J Geriatr Phys Ther 31: 3-10, 2008. PMID: 18489802. DOI: 10.1519/00139143-200831010-00002

12 Knudsen AW, Naver A, Bisgaard K, Nordgaard-Lassen I, Becker U, Krag A and Slinde F: Nutrition impact symptoms, handgrip strength and nutritional risk in hospitalized patients with gastroenterological and liver diseases. Scand J Gastroenterol 50: 1191-1198, 2015. PMID: 25876708. DOI: 10.3109/00365521. 2015.1028994

13 Porto JM, Nakaishi APM, Cangussu-Oliveira LM, Freire Júnior RC, Spilla SB and Abreu DCC: Relationship between grip strength and global muscle strength in community-dwelling older people. Arch Gerontol Geriatr 82: 273-278, 2019. PMID: 30889410. DOI: $10.1016 /$ j.archger.2019.03.005

14 Clark BC and Manini TM: What is dynapenia? Nutrition 28: 495-503, 2012. PMID: 22469110. DOI: 10.1016/j.nut. 2011.12.002

15 Yoh K, Nishikawa H, Enomoto H, Iwata Y, Ikeda N, Aizawa N, Nishimura T, Iijima H and Nishiguchi S: Grip strength: A useful marker for composite hepatic events in patients with chronic liver diseases. Diagnostics (Basel) 10: 238, 2020. PMID: 32325995. DOI: 10.3390/diagnostics 10040238

16 Hanai T, Shiraki M, Imai K, Suetsugu A, Takai K, Moriwaki H and Shimizu M: Reduced handgrip strength is predictive of poor survival among patients with liver cirrhosis: A sex-stratified analysis. Hepatol Res 49: 1414-1426, 2019. PMID: 31408558. DOI: $10.1111 /$ hepr.13420

17 Leong DP, Teo KK, Rangarajan S, Lopez-Jaramillo P, Avezum A Jr, Orlandini A, Seron P, Ahmed SH, Rosengren A, Kelishadi R, Rahman O, Swaminathan S, Iqbal R, Gupta R, Lear SA, Oguz A, Yusoff K, Zatonska K, Chifamba J, Igumbor E, Mohan V, Anjana RM, Gu H, Li W and Yusuf S; Prospective Urban Rural Epidemiology (PURE) Study investigators: Prognostic value of grip strength: findings from the Prospective Urban Rural Epidemiology (PURE) study. Lancet 386: 266-273, 2015. PMID: 25982160. DOI: 10.1016/S0140-6736(14)62000-6

18 García-Hermoso A, Ramírez-Vélez R, Peterson MD, Lobelo F, Cavero-Redondo I, Correa-Bautista JE and Martínez-Vizcaíno V: Handgrip and knee extension strength as predictors of cancer mortality: a systematic review and meta-analysis. Scand J Med
Sci Sports 28: 1852-1858, 2018. PMID: 29723933. DOI: $10.1111 / \mathrm{sms} .13206$

19 Malhotra R, Tareque MI, Tan NC and Ma S: Association of baseline hand grip strength and annual change in hand grip strength with mortality among older people. Arch Gerontol Geriatr 86: 103961, 2020. PMID: 31704626. DOI: 10.1016/j.archger.2019.103961

$20 \mathrm{Wu}$ Y, Wang W, Liu T and Zhang D: Association of grip strength with risk of all-cause mortality, cardiovascular diseases, and cancer in community-dwelling populations: A meta-analysis of prospective cohort studies. J Am Med Dir Assoc 18: 551.e17-551.e35, 2017. PMID: 28549705. DOI: 10.1016/j.jamda.2017.03.011

21 Yusuf S, Joseph P, Rangarajan S, Islam S, Mente A, Hystad P, Brauer M, Kutty, VR, Gupta R, Wielgosz A, AlHabib KF, Dans A, Lopez-Jaramillo P, Avezum A, Lanas F, Oguz A, Kruger IM, Diaz R, Yusoff K, Mony P, Chifamba J, Yeates K, Kelishadi R, Yusufali A, Khatib R, Rahman O, Zatonska K, Iqbal R, Wei L, Bo H, Rosengren A, Kaur M, Mohan V, Lear SA, Teo KK, Leong D, O'Donnell M, McKee M and Dagenais G: Modifiable risk factors, cardiovascular disease, and mortality in 155722 individuals from 21 high-income, middle-income, and low-income countries (PURE): a prospective cohort study. Lancet 395: 795-808, 2020. PMID: 31492503. DOI: 10.1016/S0140-6736(19)32008-2

22 Celis-Morales CA, Welsh P, Lyall DM, Steell L, Petermann F, Anderson J, Iliodromiti S, Sillars A, Graham N, Mackay DF, Pell JP, Gill JMR, Sattar N and Gray SR: Associations of grip strength with cardiovascular, respiratory, and cancer outcomes and all cause mortality: prospective cohort study of half a million UK Biobank participants. BMJ 361: k1651, 2018. PMID: 29739772. DOI: 10.1136/bmj.k1651

23 Kim GR, Sun J, Han M, Park S and Nam CM: Impact of handgrip strength on cardiovascular, cancer and all-cause mortality in the Korean longitudinal study of ageing. BMJ Open 9: e027019, 2019. PMID: 31072857. DOI: 10.1136/bmjopen2018-027019

24 Nishikawa H, Enomoto H, Ishii A, Iwata Y, Miyamoto Y, Ishii N, Yuri Y, Takata R, Hasegawa K, Nakano C, Nishimura T, Yoh K, Aizawa N, Sakai Y, Ikeda N, Takashima T, Iijima H and Nishiguchi S: Prognostic significance of low skeletal muscle mass compared with protein-energy malnutrition in liver cirrhosis. Hepatol Res 47: 1042-1052, 2017. PMID: 27862791. DOI: 10.1111/hepr.12843

25 Kobayashi T, Kawai H, Nakano O, Abe S, Kamimura H, Sakamaki A, Kamimura K, Tsuchiya A, Takamura M, Yamagiwa $\mathrm{S}$ and Terai S: Rapidly declining skeletal muscle mass predicts poor prognosis of hepatocellular carcinoma treated with transcatheter intra-arterial therapies. BMC Cancer 18: 756, 2018. PMID: 30041616. DOI: 10.1186/s12885-018-4673-2

26 Ebadi M, Wang CW, Lai JC, Dasarathy S, Kappus MR, Dunn MA, Carey EJ and Montano-Loza AJ; From the Fitness, Life Enhancement, and Exercise in Liver Transplantation (FLEXIT) Consortium: Poor performance of psoas muscle index for identification of patients with higher waitlist mortality risk in cirrhosis. J Cachexia Sarcopenia Muscle 9: 1053-1062, 2018. PMID: 30269421. DOI: 10.1002/jcsm.12349

27 Hamaguchi Y, Kaido T, Okumura S, Kobayashi A, Shirai H, Yao S, Yagi S, Kamo N, Seo S, Taura K, Okajima H and Uemoto S: Preoperative visceral adiposity and muscularity predict poor outcomes after hepatectomy for hepatocellular carcinoma. Liver Cancer 8: 92-109, 2019. PMID: 31019900. DOI: 10.1159/00 0488779 
28 Ishizu Y, Ishigami M, Kuzuya T, Honda T, Hayashi K, Ishikawa T, Hirooka Y and Goto H: Low skeletal muscle mass predicts early mortality in cirrhotic patients with acute variceal bleeding. Nutrition. 42: 87-91, 2017. PMID: 28870485. DOI: 10.1016/j.nut.2017.06.004

29 Montano-Loza AJ, Angulo P, Meza-Junco J, Prado CM, Sawyer $\mathrm{MB}$, Beaumont C, Esfandiari N, Ma M and Baracos VE: Sarcopenic obesity and myosteatosis are associated with higher mortality in patients with cirrhosis. J Cachexia Sarcopenia Muscle 7: 126-135, 2016. PMID: 27493866. DOI: 10.1002/jcsm.12039

30 Fujiwara N, Nakagawa H, Kudo Y, Tateishi R, Taguri M, Watadani T, Nakagomi R, Kondo M, Nakatsuka T, Minami T, Sato M, Uchino K, Enooku K, Kondo Y, Asaoka Y, Tanaka Y, Ohtomo K, Shiina S and Koike K: Sarcopenia, intramuscular fat deposition, and visceral adiposity independently predict the outcomes of hepatocellular carcinoma. J Hepatol 63: 131-140, 2015. PMID: 25724366. DOI: 10.1016/j.jhep.2015.02.031

31 Hiraoka A, Michitaka K, Izumoto H, Ueki H, Kitahata S, Aibiki T, Okudaira T, Yamago H, Miyamoto Y, Iwasaki R, Tomida H, Mori K, Miyata H, Tsubouchi E, Kishida M, Hirooka M, Abe M, Matsuura B, Ninomiya T and Hiasa Y: Relative changes in handgrip strength and skeletal muscle volume in patients with chronic liver disease over a 2-year observation period. Hepatol Res 48: 502-508, 2018. PMID: 25724366. DOI: 10.1016/j.jhep.2015.02.031

32 Fukui H, Saito H, Ueno Y, Uto H, Obara K, Sakaida I, Shibuya A, Seike M, Nagoshi S, Segawa M, Tsubouchi H, Moriwaki H, Kato A, Hashimoto E, Michitaka K, Murawaki T, Sugano K, Watanabe $\mathrm{M}$ and Shimosegawa T: Evidence-based clinical practice guidelines for liver cirrhosis 2015. J Gastroenterol 51: 629-650, 2016. PMID: 27246107. DOI: 10.1007/s00535-0161216-y

33 Kokudo N, Takemura N, Hasegawa K, Takayama T, Kubo S, Shimada M, Nagano H, Hatano E, Izumi N, Kaneko S, Kudo M, Iijima H, Genda T, Tateishi R, Torimura T, Igaki H, Kobayashi S, Sakurai H, Murakami T, Watadani T and Matsuyama Y: Clinical practice guidelines for hepatocellular carcinoma: The Japan Society of Hepatology 2017 (4th JSH-HCC guidelines) 2019 update. Hepatol Res 49: 1109-1113, 2019. PMID: 31336394. DOI: 10.1111/hepr.13411

34 European Association for the Study of the Liver: EASL Recommendations on Treatment of Hepatitis C 2018. J Hepatol 69: 461-511, 2018. PMID: 29650333. DOI: 10.1016/j.jhep.2018.03.026
35 Drafting Committee for Hepatitis Management Guidelines and the Japan Society of Hepatology: Japan Society of Hepatology Guidelines for the Management of Hepatitis B Virus Infection: 2019 update. Hepatol Res 50: 892-923, 2020. PMID: 32343469. DOI: $10.1111 /$ hepr.13504

36 Nishikawa H, Shiraki M, Hiramatsu A, Moriya K, Hino K and Nishiguchi S: Japan Society of Hepatology guidelines for sarcopenia in liver disease (1st edition): Recommendation from the working group for creation of sarcopenia assessment criteria. Hepatol Res 46: 951-963, 2016. PMID: 27481650. DOI: 10.1111/hepr.12774

37 Nishikawa H, Yoh K, Enomoto H, Ishii N, Iwata Y, Nakano C, Takata R, Nishimura T, Aizawa N, Sakai Y, Ikeda N, Hasegawa $\mathrm{K}$, Takashima T, Iijima H and Nishiguchi S: Extracellular water to total body water ratio in viral liver diseases: A study using bioimpedance analysis. Nutrients 10: 1072, 2018. PMID: 30103528. DOI: 10.3390/nu10081072

38 Nishikawa H, Enomoto H, Yoh K, Iwata Y, Sakai Y, Kishino K, Ikeda N, Takashima T, Aizawa N, Takata R, Hasegawa K, Ishii $\mathrm{N}$, Yuri Y, Nishimura T, Iijima H and Nishiguchi S: Walking speed: Japanese data in chronic liver diseases. J Clin Med 9: pii: E166, 2020. PMID: 31936162. DOI: 10.3390/jcm9010166

39 Toyama T, van den Broek-Best O, Ohkuma T, Handelsman D, Waite LM, Seibel MJ, Cumming R, Naganathan V, Sherrington $\mathrm{C}$, Hirani $\mathrm{V}$ and Wang AY: Associations of impaired renal function with declines in muscle strength and muscle function in older men: Findings From the CHAMP Study. J Gerontol A Biol Sci Med Sci 74: 1812-1820, 2019. PMID: 31086955. DOI: 10.1093/gerona/glz100

40 Sung JH, Uojima H, Hidaka H, Tanaka Y, Wada N, Kubota K, Nakazawa T, Shibuya A, Fujikawa T, Yamanoue H, Kako M and Koizumi W: Risk factors for loss of skeletal muscle mass in patients with cirrhosis. Hepatol Res 49: 550-558, 2019. PMID: 30623996. DOI: 10.1111/hepr.13308

Received September 23, 2020

Revised October 4, 2020

Accepted October 12, 2020 